\title{
Thoracic splenule without prior history of trauma or surgery
}

\author{
Achilleas Lioulias, MD, PhD, ${ }^{\text {a }}$ Panagiotis Misthos, MD, PhD, a,b Kostas Neofotistos, MD, ${ }^{a}$ \\ Georgios Papagiannakis, MD, PhD, ${ }^{\mathrm{a}}$ and John Kokotsakis, MD, PhD, ${ }^{\mathrm{b}}$ Athens, Greece
}

$\mathrm{E}$ ctopic extra-abdominal splenic tissue is a rare clinical condition. Most frequently, it is caused by splenosis, which is defined as the autotransplantation of splenic tissue after disruption of the splenic capsule. It occurs more commonly in the peritoneum, omentum, and the mesentery, whereas thoracic splenosis has always been documented after trauma or abdominal surgery, especialy after splenectomy. However, splenic tissue in the thorax that is perfused by thoracic vessels, without trauma or abdominal surgery, can be present as an embryologic anomaly and is an exceptionally unusual situation. We report a case of thoracic splenule without any of the above-mentioned provocative factors misdiagnosed as a thoracic mass. To our knowledge, this is the second case to be reported. ${ }^{1}$

\section{Clinical Summary}

A 47-year-old man with thalassemia was admitted for chest pain. Results of the physical examination were unremarkable, and the patient had no history of trauma or any kind of previous surgical procedure. At chest radiography an intrapleural mass was recognized. The computed tomographic scan of the thorax showed a solid homogeneous mass in the right paraspinal region attached to the posterior wall (Figure 1).

The patient was subjected to an open mini muscle-sparing left thoracotomy for both diagnostic and therapeutic purposes. A round dark-colored firm mass was recognized in the paravertebral gutter, measuring $5 \mathrm{~cm}$ in diameter. It was easily dissected from the chest wall. The intercostal vessels provided the blood supply through a hypertrophic branch. The histologic results disclosed tissue composed of prominent splenic red pulp together with histiocyte infiltration and extramedullary hemopoiesis (Figure 2). The changes were typical of the splenomegaly of hemolytic anemia.

The postoperative course was uneventful and the patient was discharged home on the fifth postoperative day.

\section{Discussion}

Splenic tissue in the thoracic cavity is usually due to splenosis. A history of thoracoabdominal trauma or surgery and findings of

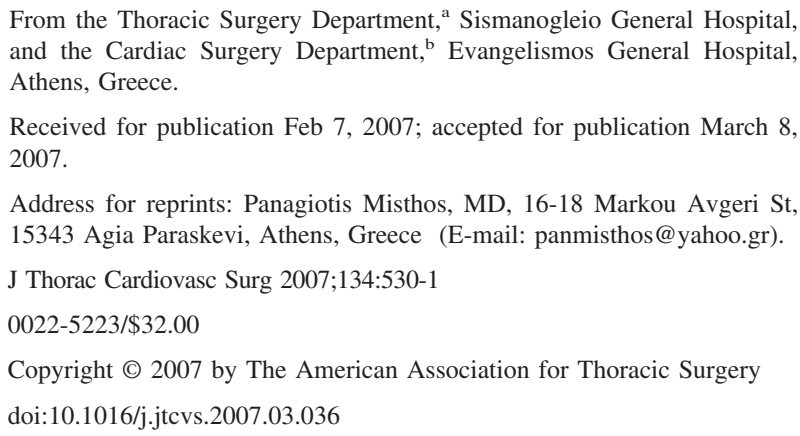

left-sided, extrapulmonary, pleura-based nodules should indicate the diagnosis of thoracic splenosis. ${ }^{2}$

Alternatively, a thoracic splenule denotes a congenital focus of healthy splenic tissue that is separate from the main body of the spleen and is perfused by thoracic vessels. Only one other case of thoracic splenule, which was perfused by intercostal vessels, has been reported. This clinical entity should be differentiated from a supernumerary spleen in the thorax ${ }^{3}$ with a long vascular pedicle originating from the abdomen and should be clinically discriminated from extralobular pulmonary sequestration. It is a completely different embryologic situation, in which extra-abdominal spleen arises from the failure of fusion of the splenic anlage.

There is no clear answer to the mechanism of thoracic splenule formation. Primordial splenic cells may migrate into the pleural cavity through the incomplete pleuroperitoneal folds, between the fifth and seventh weeks of embryologic development. ${ }^{1}$ The splenic remnants may implant on the parietal or the visceral pleura, and the pericardium spleniculum is perfused by blood supply from surrounding tissue and gradually grows into mature splenic tissue. In our case, a hypertrophic intercostal artery fed the splenule. In patients who have thalassemia, idiopathic thrombocytopenic purpura, or hereditary spherocytosis who have undergone splenectomy, growth of previously unrecognized accessory splenic tissue has been known to occur.

Thoracic splenosis and spleniculi, to our knowledge, have not been frequently associated with symptoms. They usually present with abdominal or thoracic pain. Although most of these anatomic variants have no clinical significance, it is important to be aware of them and recognize them. Differential diagnoses include pleural metastases, asbestos-related pleural plaques, mesothelioma, neurinoma, and fibrous tumor. Alternatively, a missed accessory spleen may be the site of relapse of a hematologic disorder. Unfortuna-

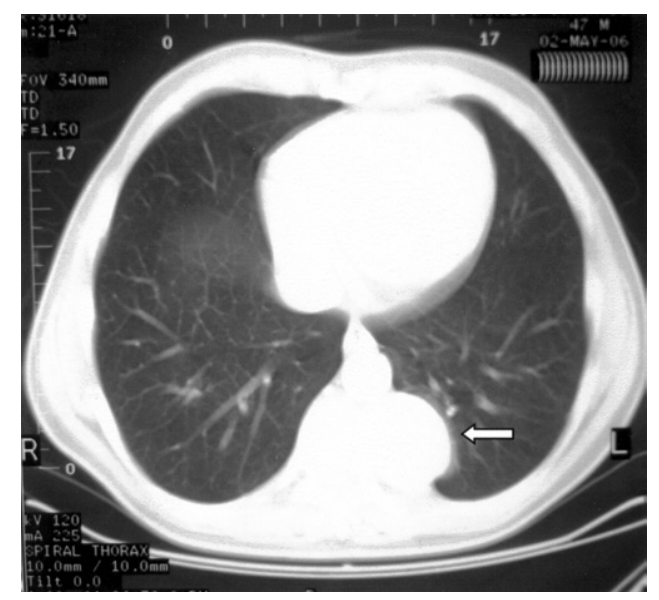

Figure 1. Thoracic computed tomographic scan depicting a pleural mass. 


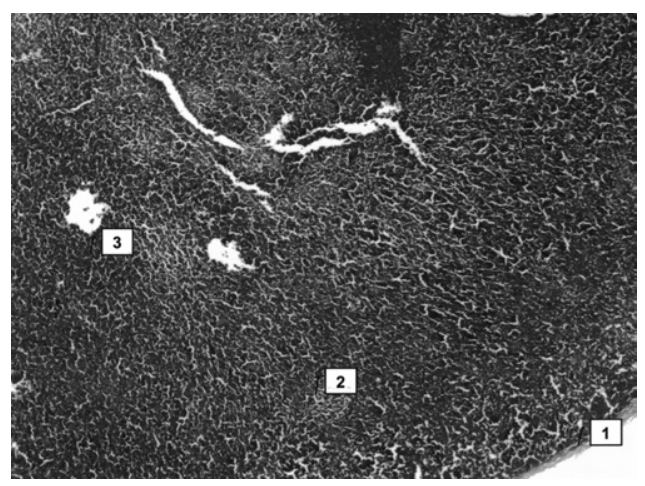

Figure 2. Histologic study of the resected specimen. 1, Capsule; 2, white pulp; 3, red pulp.

taly, most splenic nodules are mistaken for pleural parenchymal neoplastic lesions. Video-assisted thoracic surgery or thoracotomy is usually required to set the diagnosis.
The computed tomographic scan shows nonspecific round or ovoid masses with well-defined borders. Their location is variable. A splenule enhances homogeneously on contrast-enhanced images to a similar density as that of the spleen. Magnetic resonance, along with the administration of super-paramagnetic iron oxide, may be helpful and results in loss of signal intensity in all pulse sequences, similar to that seen within normal spleen. A radiologic diagnosis can be confirmed by either a technetium sulfur colloid, iodine-labeled, or technetium heat-damaged erythrocyte study, which all result in increased uptake of the radioactive isotope in the ectopic splenic tissue.

\section{References}

1. Balacumaraswami L, Yeatman M, Ghosh AK, Collins C, ForresterWood CP. Accessory spleniculi in the right hemithorax. Ann Thorac Surg. 2002;74:2172-41.

2. Madjar S, Weissberg D. Thoracic splenosis. Thorax. 1994;49: 1020-2.

3. Lee HJ, Kim YT, Kang CH, Kim JH. An accessory spleen misrecognized as an intrathoracic mass. Eur J Cardiothorac Surg. 2005;28:640.

\section{Interventional closure of postpneumonectomy bronchial pleural fistula with a self-expandable double umbrella-shaped occluder knitted with nitinol shape memory alloy}

Jianhua Zhang, MD, PhD, ${ }^{a}$ Shengshou $\mathrm{Hu}, \mathrm{MD}, \mathrm{PhD},{ }^{\mathrm{b}}$ Bingren Gao, MD, PhD, ${ }^{a}$ Debin Liu, MD, PhD, ${ }^{\mathrm{b}}$ Feixue Song, MD, ${ }^{\mathrm{a}}$ Bin Li, MD, ${ }^{\text {a }}$ Yongzhu Yang, MD, Shenjun Zhu, MD, PhD, ${ }^{\mathrm{c}}$ and Zhiping Wang, MD, PhD, ${ }^{\mathrm{a}}$ Lanzhou and Beijing, China

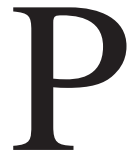

${ }^{1}$ ostpneumonectomy bronchial pleural fistula (PBPF) is one of the most serious complications in cardiac surgery. ${ }^{1}$ Surgical repair of PBPF would be of high risk. The interventional procedures available have limited effects on fistulas with larger orifices. We designed a double-um-

From the Department of Thoracic and Cardiovascular Surgery, ${ }^{a}$ The Second Hospital of Lanzhou University, Lanzhou, China; Department of Surgery, ${ }^{\text {b }}$ Cardiovascular Institute and Fuwai Hospital; The Medical College of Tsinghua University, ${ }^{\mathrm{c}}$ Beijing, China.

Received for publication Jan 9, 2007; revisions received March 14, 2007; accepted for publication March 16, 2007.

Address for reprints: Jian-hua Zhang, MD, PhD, Department of Thoracic and Cardiovascular Surgery, The Second Hospital of Lanzhou University, Lanzhou 730030, China (E-mail: Zhangjianhua68@yahoo.com.cn). Sheng-shou Hu, MD, PhD, Department of Cardiovascular Surgery, Cardiovascular Institute and Fu-Wai Hospital, Beijing 100037, China (E-mail: huss@163bj.com).

J Thorac Cardiovasc Surg 2007;134:531-3

$0022-5223 / \$ 32.00$

Copyright $\odot 2007$ by The American Association for Thoracic Surgery doi:10.1016/j.jtcvs.2007.04.013 brella occluder and used it in 6 patients from April 2002 through November 2006. The results are as follows.

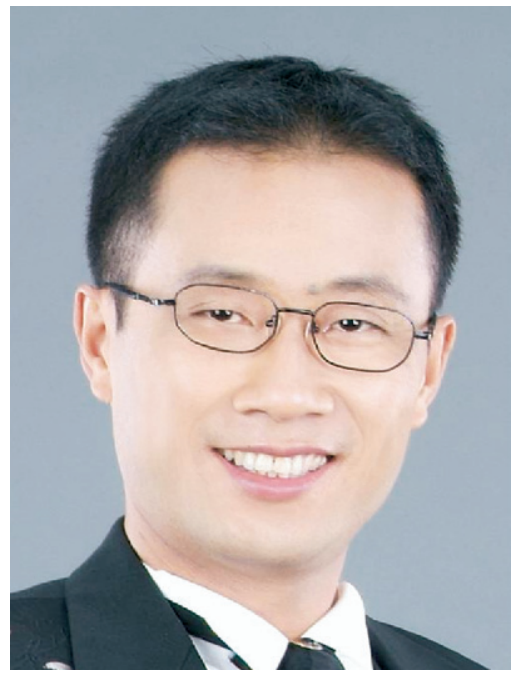

Dr Zhang

\section{Clinical Summary}

A total of 6 patients (4 male and 2 female patients; age range, approximately 34-74 years) were included in this study. Patients had tuberculous thick walled cavity $(n=1)$, tuberculosis-destroyed lungs $(n=2)$, chronic lung abscess $(n=1)$, and central-type lung cancer $(n=2)$. One patient had preoperative radiotherapy, 1 patient had diabetes mellitus and an older age (74 years), and 1 patient had concomitant dyscrasia. A left entire pneumonectomy was performed in 4 patients, and a right entire pnemuonectomy was performed in 2 patients. The bronchial stump was closed by using manual suturing in 4 patients and a suture stapler in 2 patients. Fistulas and empyema occurred on postoperative days 7 to 21 .

The occluder consists of a proximal umbrella, distal umbrella, proximal metal marker, distal metal marker, waist, and proximal nut (Figure 1,A). The internal filler was layers of polyester fabric, 